\title{
ДЕМОГРАФИЯ СТЕНЫ ТРАМПА
}

\author{
ДаДЛИ ПОСТОН МЛ., ПИТЕР МОРРИСОН
}

В статье американских демографов обсуждаются причины, по которым предлагаемое президентом Трампом строительство стены на границе с Мексикой не может быть эффективной мерой, ограничивающей иммигращию в США.

Ключевые слова: стена Трампа, иммигращчя, недокументированная иммигращия.

Одной из главных особенностей президентской кампании Дональда Трампа стало его обещание построить стену на южной границе США, чтобы раз и навсегда остановить «незаконную» иммиграцию мексиканцев и представителей других стран Центральной Америки. Он говорил своим сторонникам, что Мексика заплатит за эту стену. Но сейчас он отказался от этого заявления, за нее будут платить США, а не Мексика. И стена будет недешевой. Министерство внутренней безопасности США заявило, что строительство стены обойдется в 21,6 млрд долларов и займет три года [Ainsley 2017].

В этом коротком эссе мы утверждаем, что стена Трампа не сработает. Она не уменьшит количество недокументированных иммигрантов в США, а даст обратный эффект, увеличит их число. Обратимся вначале к демографическим данным об иммиграции в США как легальной, так и недокументированной.

\section{ЛИЦА С ПРОСРОЧЕННОЙ ВИЗОЙ В США}

По состоянию на 2015 г. в США проживало около 44 млн человек, родившихся за пределами страны. Три четверти из них, или около 33 млн - это законные иммигранты, называемые также «легальными» или «узаконенными» иммигрантами. К ним относятся натурализованные граждане, лица, имеющие законный статус постоянного или временного проживания (например, в качестве рабочих или студентов), а также лица, получившие убежище или принятые в качестве беженцев.

Остальные $25 \%$ родившихся за рубежом жителей США или чуть более 11 млн человек - это незаконные, также известные как «нелегальные» или «недокументированные» иммигранты. Об этих 11,1 млн «нелегалов» и говорит все время президент Трамп, именно их он хочет депортировать через южную границу.

\footnotetext{
ДАДЛИ Д. Постон МЛ. (d-poston@tamu.edu), ТЕХАССКИЙ СЕЛЬСКОХОЗЯЙСТвЕННЫЙ и МАШИНОСТРОИТЕЛЬНЫЙ УНИВЕРСИТЕТ, США.

ПИТЕР А. МОРРИСОН, ПРИКЛАДНОЙ ДЕМОГРАФ (ПЕНСИОНЕР РЭНД), США.

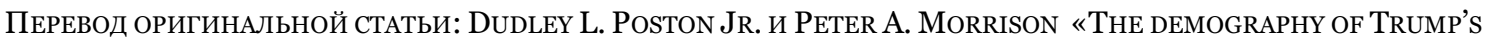
WALL», ОПУБЛИКОВАННОЙ В БЮЛЛЕТЕНЕ N-IUSSP 3 АПРЕЛЯ 2017 Г. URL: HTTP://WWW.NIUSSP.ORG/ARTICLE/DEMOGRAPHY-TRUMPS-WALLLE-MUR-DE-TRUMP-ET-SES-CONSEQUENCESDEMOGRAPHIQUES. ПЕРЕВОД О. ПЕТРОВОЙ.
} 


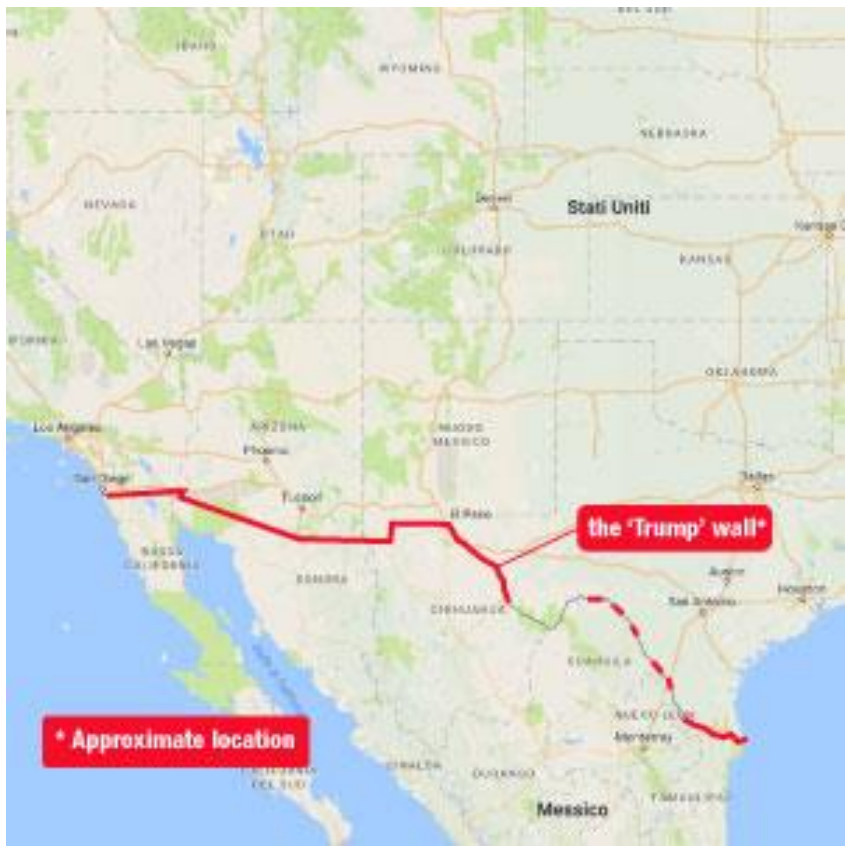

По-видимому, президенту Трампу неизвестен тот факт, что около двух пятых из этих 11,1 млн иммигрантов, не имеющих документов, или почти 4,5 млн - это те, кто обладает просроченными визами. Они въехали в США с законными паспортами и действующими визами, но либо остались в стране после истечения срока действия визы, либо нарушили условия въезда в США каким-то иным образом. Большинство из них законно прилетели из Азии, Европы и других континентов и пересекли границу в крупных аэропортах в СанФранциско, Нью-Йорке, Лос-Анджелесе, Хьюстоне и других городах. Стена Трампа недостаточно высока, чтобы удержать их.

В США в настоящее время нет плана по решению проблемы нелегальной иммиграции, сформировавшейся вследствие просроченных виз. Учетные данные Министерства внутренней безопасности США о прибытии и убытии лиц, въезжающих в США и выезжающих из них, не совпадают между собой. Конгресс принял решение о создании электронной системы учета въезда-выезда более 20 лет назад, но она не была реализована из-за возражений со стороны индустрии туризма и других групп. Система биометрического контроля въезда/выезда, видимо, смогла бы отслеживать большинство людей, въезжающих и выезжающих из США и, вероятно, уменьшила бы число лиц с просроченными визами. Но создание такой системы не входит в планы президента Трампа. Он хочет просто построить стену. А это значит, что число лиц с просроченными визами, видимо, так и останется на уровне около 4-5 млн, несмотря на стену Трампа.

\section{БОЛЫШЕ, А НЕ МЕНЫШЕ БЕСКОНТРОЛЬНО ВЪЕХАВШИХ В ОБОЗРИМОМ БУДУЩЕМ}

А как обстоит дело с остальными 6-7 млн нелегальных иммигрантов в США? Кто они такие? Как они въехали в Соединенные Штаты? Откуда они? Это и есть так называемые «нелегальные» иммигранты, о которых все говорят. Официально иммиграционные власти называют их EWI (entry without inspection), «бесконтрольно въехавшими». Они проникли в 
США без досмотра или использовали поддельные документы при пересечении границы. Почти все они въехали через американо-мексиканскую границу, и до недавнего времени большинство из них были выходцами из Мексики.

Почему стена Трампа не станет препятствием для EWI, независимо от страны их происхождения? Почему стена Трампа приведет к увеличению, а не к уменьшению их числа?

Привычный стереотип нелегального иммигранта, пересекающего мексиканскоамериканскую границу, уже не соответствует современным реалиям иммиграции. На протяжении десятилетий большинство EWI, въехавших в США через южную границу, были так называемыми циркулярными мигрантами. Они приезжали в США в основном на низкооплачиваемые работы в сельском хозяйстве, строительстве и смежных отраслях, оставались в стране несколько месяцев, возможно год, зарабатывали деньги и возвращались домой. Многие из них были сезонными сельскохозяйственными рабочими из Мексики, они, в частности, по мере того, как поспевал урожай, перемещались по стране от Калифорнийской долины до долины Якима в штате Вашингтон [Morrison, Poston 2017].

Дуглас Массей и его коллеги [Massey, Durand, Pren 2016] описали эти иммиграционные модели. Они показали, что усиление пограничного контроля серьезно нарушило циркулярные потоки рабочих, которые приезжали преимущественно в Калифорнию и Техас, а затем уезжали домой. Усиление пограничного контроля «повысило расходы на пересечение границы без документов, заставляя недокументированных иммигрантов дольше оставаться в США, чтобы сделать поездку выгодной». С усилением пограничного контроля и надзора увеличились и расходы на пересечение границы. В результате мигранты минимизировали пересечение границы «не потому что они стали оставаться в Мексике, а потому что теперь они остаются в Соединенных Штатах». Проще говоря, теперь речь идет уже не о циркулярных мигрантах, они трансформируются в постоянно проживающих нелегальных иммигрантов [Massey, Durand, Pren 2016; Hotchkiss 2016].

\section{БОЛЫШЕ, ЧЕМ ПРОСТО ГИПОТЕЗА}

Две диаграммы демонстрируют эту связь. На рисунке 1 представлены подготовленные демографами Исследовательского центра Пью (Pew Research Center) в Вашингтоне, округ Колумбия, ежегодные оценки числа незарегистрированных иммигрантов в США с 1990 по 2014 г. [Krogstand, Passel, Cohn 2016]. Число незарегистрированных иммигрантов в США выросло с 3,5 млн в 1990 г. до 11,1 млн в 2014 г. За 24-летний период с 1990 по 2014 г. наблюдался феноменальный рост - более чем на $210 \%$. 


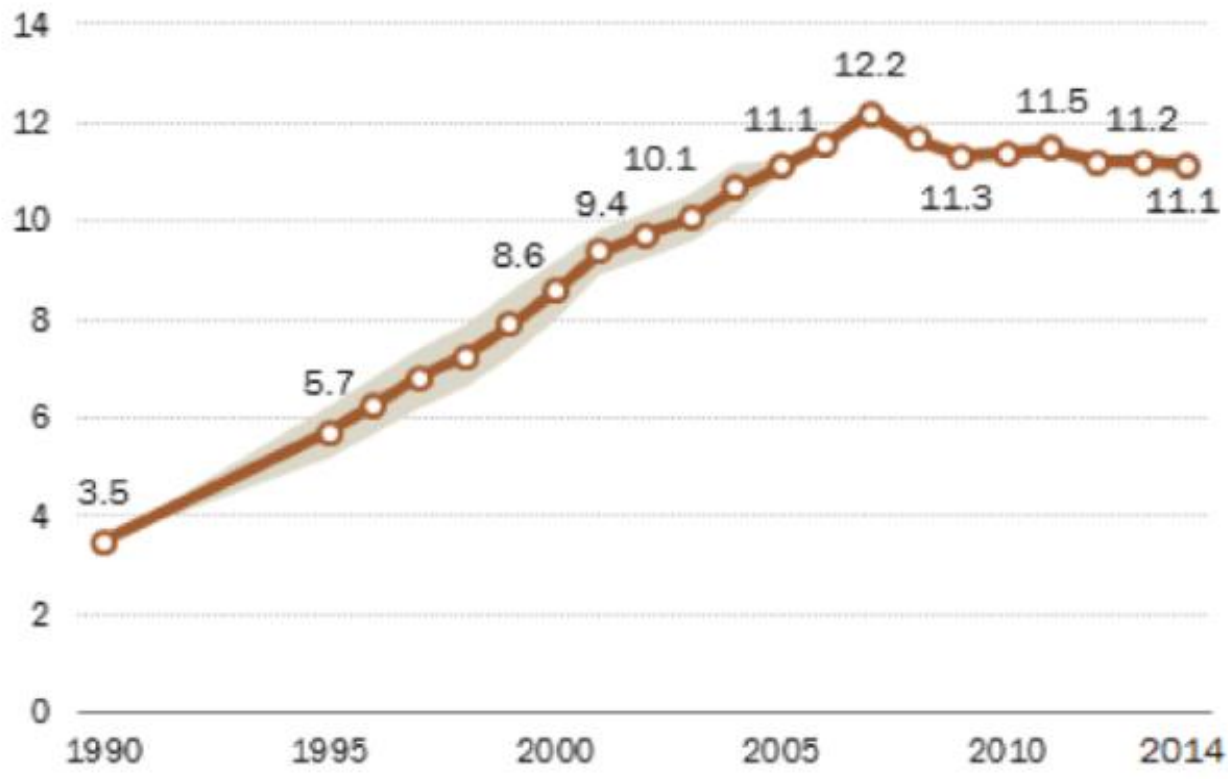

Рисунок 1. Предполагаемое количество незарегистрированных иммигрантов в Соединенных Штатах с 1990 по 2014 г., млн

Источник: [Krogstand, Passel, Cohn 2016].

На второй диаграмме (рисунок 2) представлены данные об ассигнованиях на содержание погранично-патрульной службы США [Argueta 2016]. Они наглядно показывают, что расходы на укрепление и охрану границы неуклонно росли, увеличившись с 263 млн долларов в 1990 г. до 1,4 млрд долларов в 2002 г. и до 3,8 млрд долларов в 2015 г.

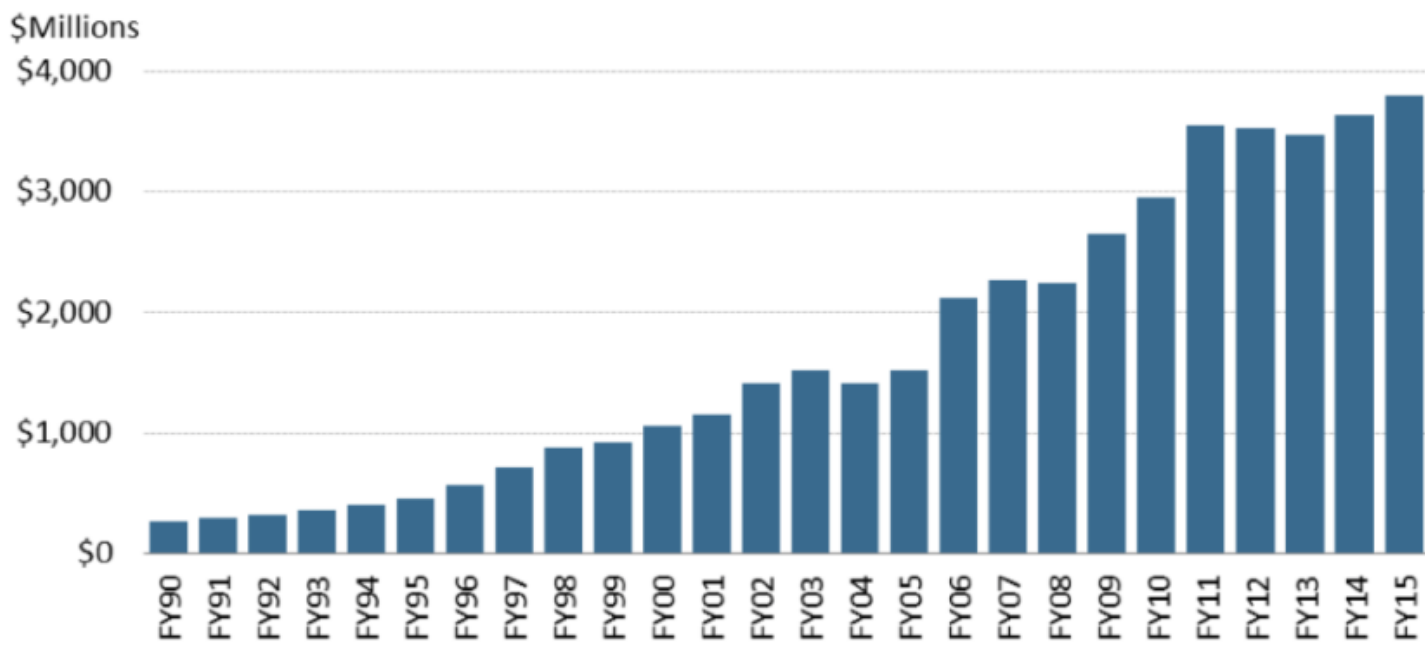

Рисунок 2. Утвержденные годовые бюджеты Пограничного-патрульной службы США, финансовые годы (FY) с 1990 по 2015 г., млн долларов

Источник: [Argueta 2016].

Сопоставление данных на первой диаграмме с данными на второй показывает, что стремительная эскалация пограничного контроля и правопорядка, имевшая целью остановить поток нелегальной иммиграции через границу США с Мексикой, не сработала. 
Милитаризация границы привела к увеличению, а не к уменьшению числа неразрешенных иммигрантов. Милитаризация превратила недокументированную миграцию в США из циркулярного потока мигрантов в несколько штатов с последующим их оттоком в постоянное население мигрантов практически во всех штатах континентальной части США.

Стена Трампа вполне может сделать эту тенденцию еще более выраженной. Иммиграция в США формируется исключительно из самых стойких и мотивированных. Только самые сильные и наиболее подготовленные попытаются пересечь границу. Демографы хорошо осведомлены о селективности миграции [Poston, Bouvier 2017]. Стена Трампа сделает путешествие в США более опасным, и многие попытки преодолеть стену потерпят неудачу. Но в конечном итоге большинство попыток окажутся успешными. Стена Трампа не помешает целеустремленным, мотивированным и талантливым людям проникнуть в США. Призрак стены Трампа заставит потенциальных циркулярных мигрантов обосноваться в США и остаться здесь, а не возвращаться домой в Мексику и другие страны Центральной Америки [Morrison, Poston 2017].

Мы предвидим, что в течение десяти лет после возведения такой стены будет по меньшей мере столько же EWI, сколько сейчас (6-7 млн), а может быть, и на несколько миллионов больше. Это означает, что, наряду с 5 млн лиц с просроченными визами, в США будет не менее 11 млн, а возможно, гораздо больше недокументированных иммигрантов, причем большинство из них превратится в оседлое население, постоянно живущее в США. Таким образом, инвестиции в размере 20 млрд долларов, предназначенные для того, чтобы отгородить людей от США, будут удерживать их в США. Стена Трампа не сработает.

\section{ЛИТЕРАТУРА}

Ainsley J.E. (2017). Trump Border Wall to Cost $\$ 21.6$ Billion, Take 3.5 Years to Build: Internal Report // Reuters World News. February 9.

Argueta C.V. (2016). Border Security: Immigration Enforcement between Ports of Entry// Congressional Research Service. April 19.

Hotchkiss, M. (2016). Tighter Enforcement along the U.S.-Mexico Border Backfired // Phys.Org News. April 21.

Krogstand J.M., J.S. Passel, D. Cohn (2016). 5 Facts About Illegal Immigration in the U.S. // Pew Research Center. November 3.

Massey D.S., J. Durand, K.A. Pren (2016). Why Border Enforcement Backfired // American Journal of Sociology. 121: 1557-1600.

Morrison P.A., D.L. Poston, Jr. (2017). Three Myths of U.S. Immigration: The Reality? A Border Wall Would Keep Undocumented in the U.S. - Not Out of It // San Antonio Express-News (March 5): F1.

Poston D.L., Jr., L.F. Bouvier (2017). Population and Society: An Introduction to Demography. 2nd edition. New York: Cambridge University Press. 


\section{THE DEMOGRAPHY OF TRUMP'S WALL}

\section{DUDLEY L. POSTON JR., PETER A. MORRISON}

The article by American demographers discusses the reasons why the construction of a wall on the border with Mexico proposed by President Trump cannot be an effective measure in restricting immigration to the United States.

Key words: Trump's wall, immigration, undocumented immigration.

Dudley L. Poston JR. (d-poston@tamu.edu), TeXas A\&M University, US.

Peter A. Morrison, APPlied demographer (RETIREd from RAND), US.

N-IUSSP, APRIL 3, 2017. URL: HTTP://WWW.NIUSSP.ORG/ARTICLE/DEMOGRAPHY-TRUMPS-WALLLE-MUR-DE-TRUMP-ETSES-CONSEQUENCES-DEMOGRAPHIQUES/

Translated By O. PEtrova.

\section{REFERENCES}

Ainsley J.E. (2017). Trump Border Wall to Cost $\$ 21.6$ Billion, Take 3.5 Years to Build: Internal Report // Reuters World News. February 9.

Argueta C.V. (2016). Border security: immigration enforcement between ports of entry// Congressional Research Service. April 19.

Hotchkiss, M. (2016). Tighter enforcement along the U.S.-Mexico Border Backfired // Phys.Org News. April 21.

Krogstand J.M., J.S. Passel, D. Cohn (2016). 5 facts about illegal immigration in the U.S. // Pew Research Center. November 3.

Massey D.S., J. Durand, K.A. Pren (2016). Why Border Enforcement Backfired // American Journal of Sociology. 121: 1557-1600.

Morrison P.A., D.L. Poston, Jr. (2017). Three myths of U.S. Immigration: the reality? A border wall would keep undocumented in the U.S. - not out of it // San Antonio Express-News (March 5): F1.

Poston D.L., Jr., L.F. Bouvier (2017). Population and society: an introduction to demography. 2nd edition. New York: Cambridge University Press. 